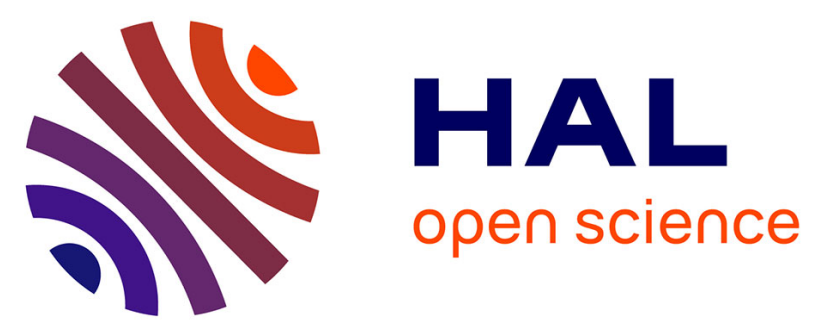

\title{
Analysis and path localization of gate current in AlGaN/GaN HEMTs using low frequency noise measurements and Optical Beam Induced Resistance Change technique
}

\author{
Serge Karboyan, Jean-Guy Tartarin, D Carisetti, B Lambert
}

\section{To cite this version:}

Serge Karboyan, Jean-Guy Tartarin, D Carisetti, B Lambert. Analysis and path localization of gate current in AlGaN/GaN HEMTs using low frequency noise measurements and Optical Beam Induced Resistance Change technique. IEEE MTT-S International Microwave Symposium Digest (IMS 2013), Jun 2013, Seattle, WA, United States. pp.1-4, 10.1109/MWSYM.2013.6697490 . hal-01343964

\author{
HAL Id: hal-01343964 \\ https://hal.science/hal-01343964
}

Submitted on 11 Jul 2016

HAL is a multi-disciplinary open access archive for the deposit and dissemination of scientific research documents, whether they are published or not. The documents may come from teaching and research institutions in France or abroad, or from public or private research centers.
L'archive ouverte pluridisciplinaire HAL, est destinée au dépôt et à la diffusion de documents scientifiques de niveau recherche, publiés ou non, émanant des établissements d'enseignement et de recherche français ou étrangers, des laboratoires publics ou privés. 


\title{
Analysis and Path Localization of Gate Current in AlGaN/GaN HEMTs Using Low Frequency Noise Measurements and Optical Beam Induced Resistance Change Technique
}

\author{
S.Karboyan ${ }^{1,2}$, J.G. Tartarin ${ }^{1,2}$, D. Carisetti ${ }^{3}$ and B. Lambert ${ }^{4}$ \\ ${ }^{1}$ LAAS - CNRS, Toulouse, 31031, France \\ ${ }^{2}$ University of Toulouse, UPS, Toulouse, 31062 , France \\ ${ }^{3}$ Thales Research and Technology, Palaiseau, 91110, France \\ ${ }^{4}$ United Monolithic Semiconductor, Villebon sur Yvette, 91140, France
}

\begin{abstract}
GaN based transistors' performance and reliability status are largely sensitive to gate conduction mechanisms and surface charges induced by spontaneous and piezoelectric effects. Understanding leakage current origin and kinetic is the key of knowledge for improving GaN technologies. Therefore, room temperature Low Frequency Noise (LFN) and Optical Beam Induced Resistance Change (OBIRCh) measurements have been investigated on the gate current of AIGaN/GaN High Electron Mobility Transistors (HEMTs). LFN measurements are performed under two configurations: the Schottky diode is measured at open drain, and the transistor is investigated in the saturated region $\left(\mathrm{V}_{\mathrm{DS}}=8 \mathrm{~V}\right)$. On the other hand, the application of the OBIRCh imaging technique is performed on the Schottky diode versus the same gate voltages than for the LFN. This paper focuses on the behavior of the gate-source region of the Schottky diode and on the gate-source and gatedrain regions of the transistor. From the LFN measurements, it is found that the carriers contributing to $I_{G S}$ are following the same path between gate and source for both configurations (diode, transistor) under elevated reverse gate-source voltage. As from OBIRCh measurements, a spots spread transmit an increase in the current conduction area on the gate width when $V_{G S}$ decreases (toward high reverse biases). The results allow correlation between these two techniques.
\end{abstract}

Index Terms - AlGaN/GaN HEMT, leakage current, LFN, OBIRCh.

\section{INTRODUCTION}

The benefits induced by the properties of wide band gap transistors result in highly efficient HF devices and circuits. However, using these technologies still poses several problems related to the reliability of devices, and limits the operating time (thus limits the market penetration). It is therefore important to understand the underlying mechanisms causing partial or fatal failures. Many studies have shown that the main sources of degradation are generated within the gate. To emphasize gate defects and current kinetic, cross expertise between different experimental workbenches has been developed. Electrical measurements are carried out, as well as Low Frequency Noise (LFN) measurements and Optical Beam Induced Resistance Change (OBIRCh) characterization on AlGaN/GaN HEMTs, considering two configurations: the analysis of the Schottky diode alone brings fundamental information about the carriers path of the leakage current in the gate-source region when the drain is open; while studying the transistor under saturated operating mode brings information on the leakage current of the device operating under realistic conditions (amplifiers, oscillators ...). LFN measurements (noise spectra versus frequency) are largely used to track defects on the conduction path of the carriers. The evolution of the noise sources with the application of a stress can also give information about the origin of the failure [1-2]. OBIRCh measurements reveal fluctuation of the resistivity in the active irradiated area using a laser beam that induces thermal changes in the device [3-4]. These two techniques are non-destructive for the device, and can be partially correlated.

The paper is organized as follows. In section II, we briefly describe the device structure and the electrical measurements. Sections III and IV report on the results of OBIRCh and LFN measurements respectively. Section V sets the conclusions drawn from the two techniques.

\section{DEVICE UnDER TEST AND EXPERIMENTAL CONDITIONS}

AlGaN/GaN HEMTs (1 finger*100 $\mu \mathrm{m}^{*} 0.5 \mu \mathrm{m}$, cf. Fig. 1 for a top view) under study are grown on $\mathrm{SiC}$ substrate and feature $18 \%$ of $\mathrm{Al}$ content. The surface is SiN passivated. The Schottky contact is formed by deposition of $\mathrm{Ni} / \mathrm{Pt} / \mathrm{Au}$.

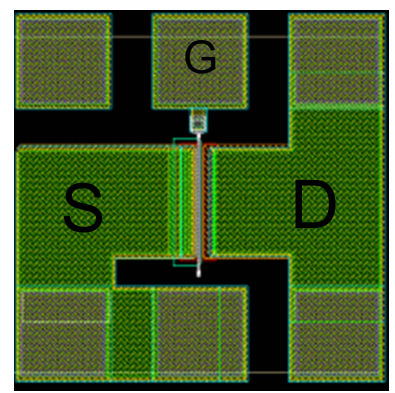

Fig. 1. Top mask view of the AlGaN/GaN HEMT under study.

DC current-voltage measurements are performed using an Agilent $4156 \mathrm{C}$. Fig. 2 shows $\mathrm{I}_{\mathrm{G}}\left(\mathrm{V}_{\mathrm{GS}}\right)$ characteristics of the Schottky diode (open drain) and of the transistor when $V_{D S}$ is biased from 0 to $8 \mathrm{~V}$. Diode with shorted drain has also been 
measured and features the same trend as with open drain (with a slight increase on $\mathrm{I}_{\mathrm{G}}$ ). This study focuses on the two extreme $\mathrm{I}_{\mathrm{G}}$ plots extracted from our measurements (the diode alone and the transistor at $\mathrm{V}_{\mathrm{DS}}=8 \mathrm{~V}$ ).

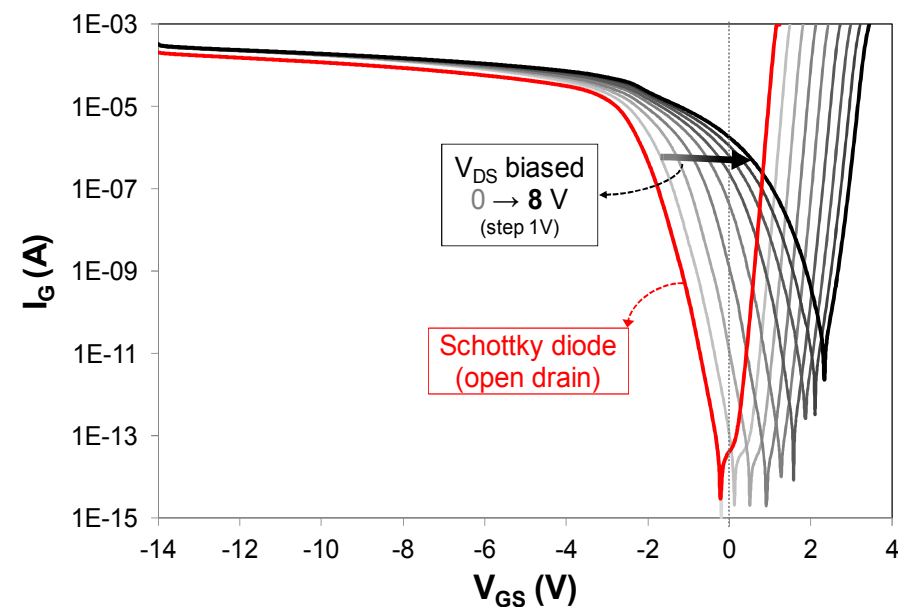

Fig. 2. $\quad \mathrm{DC} \mathrm{I}_{\mathrm{G}}-\mathrm{V}_{\mathrm{GS}}$ gate characteristics of the Schottky diode (red solid line) and of the transistor biased from $\mathrm{V}_{\mathrm{DS}}=0$ to $8 \mathrm{~V}$ with $\Delta \mathrm{V}_{\mathrm{DS}}=1 \mathrm{~V}$ (grey to black characteristics).

It can be seen that the $\mathrm{I}_{\mathrm{G}}\left(\mathrm{V}_{\mathrm{GS}}\right)$ trends shift towards positive $\mathrm{V}_{\mathrm{GS}}$ values when the drain to gate voltage increases (transistor). The signature of the leakage current evolves for these different biasing conditions. LFN and OBIRCh measurements are next performed for reverse $\mathrm{V}_{\mathrm{GS}}$ biases.

\section{GATE CURRENT PATH LOCALIZATION BY OBIRCH MEASUREMENTS}

OBIRCh measurements are performed on the same devices than static and LFN measurements. This is a thermal laser stimulation method that heats the metal of the field plate and of the metal-semiconductor interface of the gate by thermal conduction. This effect induces an increase of the current by a decrease of the resistivity. The wavelength of the laser used in this study is $1.34 \mu \mathrm{m}$. An increase in the current is revealed by the presence of red spots in the irradiated area of the device [2]. These spots highlight the zones where the current passes.

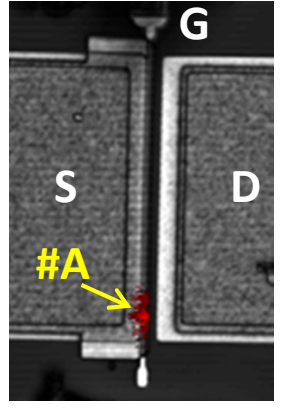

(a) $\mathrm{V}_{\mathrm{GS}}=-3 \mathrm{~V}$

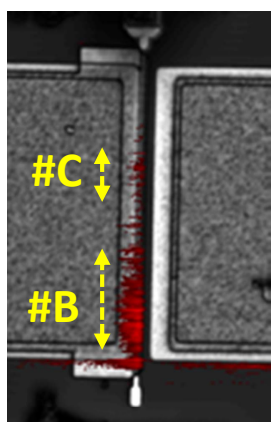

(b) $\mathrm{V}_{\mathrm{GS}}=-5 \mathrm{~V}$

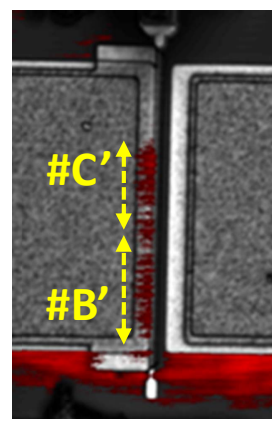

(c) $\mathrm{V}_{\mathrm{GS}}=-9 \mathrm{~V}$
Fig. 3. OBIRCh measurements between gate and source regions of the transistor: the Schottky diode is biased at $\mathrm{V}_{\mathrm{GS}}=-3,-5$ and $-9 \mathrm{~V}$
Results of OBIRCh method on AlGaN/GaN HEMTs are presented in Fig.3.

A spot revealing a very local current path at the end of the gate width can be observed in Fig. 3a ( $\# A$ for $V_{G S}=-3 V$, also visible at $-4 \mathrm{~V})$. This spot is spread at $\mathrm{V}_{\mathrm{GS}}=-5 \mathrm{~V}(\# \mathrm{~B})$ and another one appears closer to the end of the gate toward the gate pad in the upper part of the picture (\#C). As for $\mathrm{V}_{\mathrm{GS}}=-9 \mathrm{~V}$ and when the gate current increases, \#B spreads homogeneously and \#C conduction zone increases (see \#B' and ${ }^{\prime} C^{\prime}$ 'in Fig. 3c).

\section{GATE CURRENT LFN CHARACTERIZATION}

On wafer LFN measurements are performed in a shielded room. A Model 5182 transimpedance preamplifier is used. The measurements are carried out at room temperature in the frequency range of $1 \mathrm{~Hz}$ to $100 \mathrm{kHz}$.

The evolution of the gate current Low Frequency Noise $\mathrm{S}_{\mathrm{IG}}$ spectra versus frequency is given in Fig. 4 for different gate

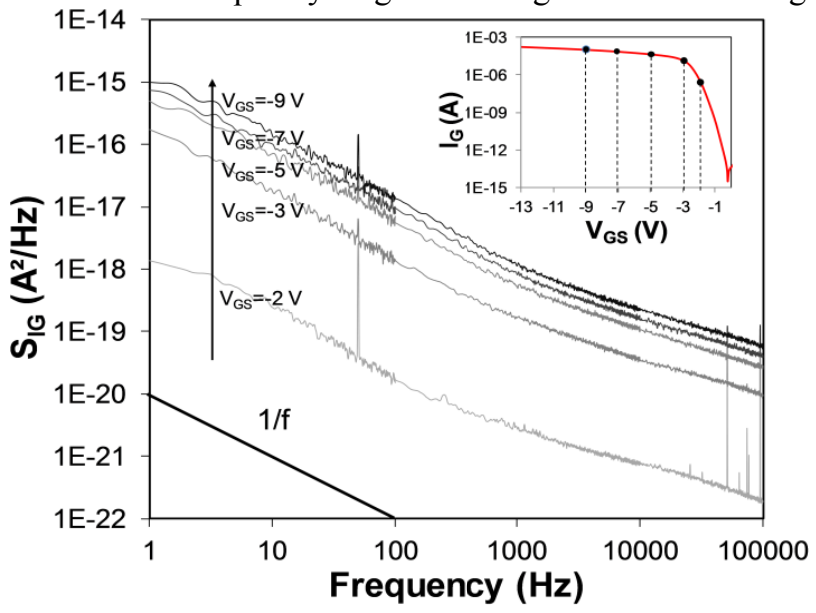

(a)

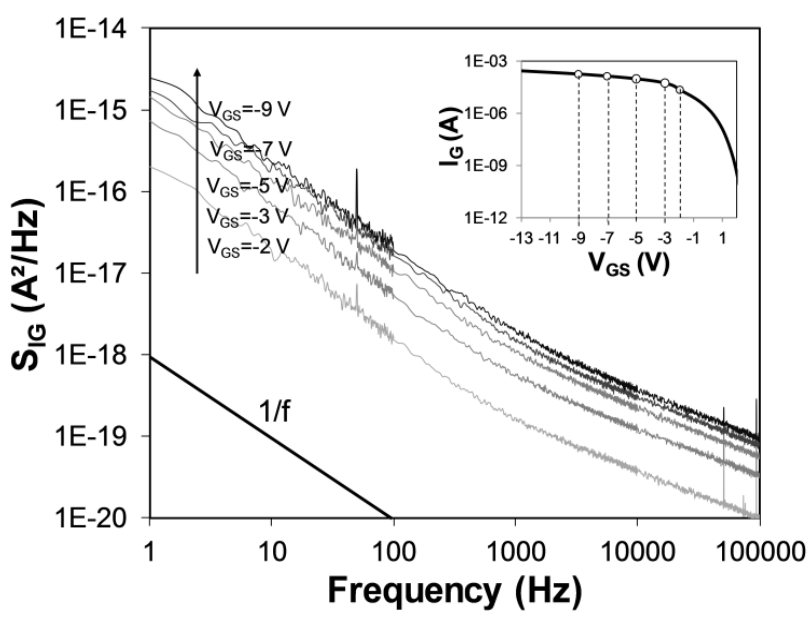

(b)

Fig. 4. Gate noise current spectral density of the AlGaN/GaN HEMT (a) of the Schottky diode (open drain) and (b) of the transistor biased in the saturation region at $\mathrm{V}_{\mathrm{DS}}=8 \mathrm{~V}$.

Insets: reverse gate $\mathrm{I}_{\mathrm{G}}-\mathrm{V}_{\mathrm{GS}}$ characteristics featuring gate biases where $\mathrm{S}_{\mathrm{IG}} \mathrm{LFN}$ measurements are carried out. 
reverse biases $\mathrm{V}_{\mathrm{GS}}$. Fig. 4(a) presents the measurements performed on the Schottky diode (open drain), whereas Fig. 4(b) illustrates the measurements on the transistor (drain biased at $\mathrm{V}_{\mathrm{DS}}=8 \mathrm{~V}$ ). The gate noise level is sensitive to $\mathrm{V}_{\mathrm{GS}}$ as $\mathrm{I}_{\mathrm{G}}$ varies, even if the $\mathrm{S}_{\mathrm{IG}}$ spectra evolution is different under these two configurations ( 3 decades for the diode, and 1 decade for the transistor over $7 \mathrm{~V}$ shift on $\mathrm{V}_{\mathrm{GS}}$ ). Table 1 synthesizes the gate current values for the different $\mathrm{V}_{\mathrm{GS}}$ biases under each configuration.

TABLE I

GATE CURRENT VALUES

\begin{tabular}{|c|c|c|c|c|c|}
\hline $\mathrm{V}_{\mathrm{GS}}(\mathrm{V})$ & -2 & -3 & -5 & -7 & -9 \\
\hline $\mathrm{I}_{\mathrm{G}}($ Schottky diode) $(\mu \mathrm{A})$ & 0.4 & 12 & 33 & 51 & 61 \\
\hline $\mathrm{I}_{\mathrm{G}}\left(\right.$ Transistor) $(\mu \mathrm{A}) @ \mathrm{~V}_{\mathrm{DS}}=8 \mathrm{~V}$ & 17 & 41 & 68 & 86 & 106 \\
\hline
\end{tabular}

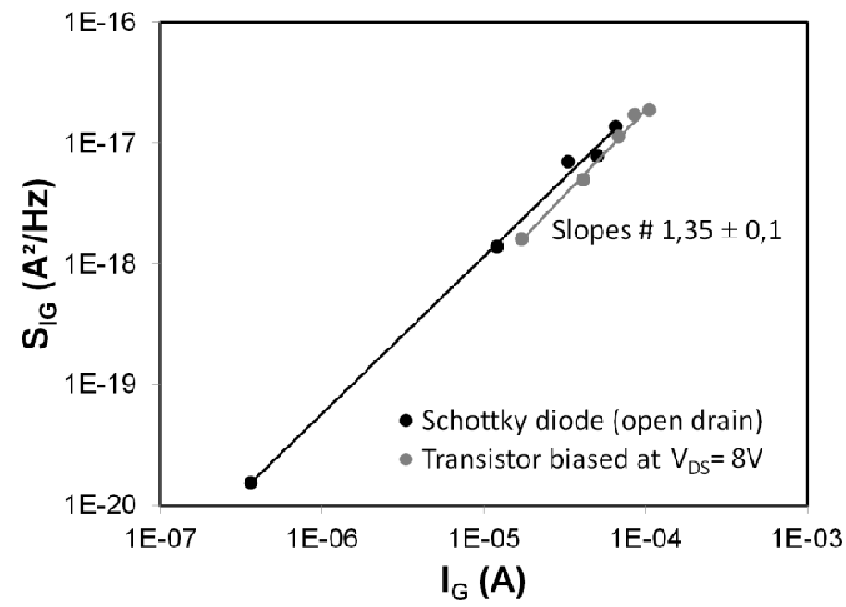

Fig. 5. Gate current noise versus gate current for the Schottky diode $\left(-9 \mathrm{~V} \leq \mathrm{V}_{\mathrm{GS}} \leq-2 \mathrm{~V}\right.$, black plots $)$ and for the transistor $\left(\mathrm{V}_{\mathrm{DS}}=8 \mathrm{~V}\right.$, $9 \mathrm{~V} \leq \mathrm{V}_{\mathrm{GS}} \leq-2 \mathrm{~V}$, grey plots).

The measurements carried out on the Schottky diode (open drain) and on the transistor (drain biased at $\mathrm{V}_{\mathrm{DS}}=8 \mathrm{~V}$ ) shown in Fig. 4(a) and 4(b) exhibit a 1/f trend superimposed with many generation-recombination centers: a robust analytical procedure has been developed [6] to accurately extract each noise contributors (the extraction accuracy depends on the relative weight of each noise source to the total spectra). Then the flicker $1 / \mathrm{f}$ noise source can be distinguished from the many GR centers, as far as its contribution has a valuable weight to the overall $\mathrm{S}_{\mathrm{IG}}$ spectra; here, up to $15 \mathrm{GR}$ centers are needed to fit the $\mathrm{S}_{\mathrm{IG}}$ spectra, and it is then delicate to track the magnitude and the frequency evolution of each GR center versus $\mathrm{V}_{\mathrm{GS}}$. The raw values are then extracted at $100 \mathrm{~Hz}$ in figure 5 . An $\mathrm{I}_{\mathrm{G}}$ power law of $1.35 \pm 0.1$ is found for the diode and for the transistor.

Since it is found that the $\mathrm{S}_{\mathrm{IG}}$ spectra depends on a power law of $\mathrm{I}_{\mathrm{G}}{ }^{1.3}$, thus the gate current spectral density can be normalized as $\mathrm{S}_{\mathrm{IG}} / \mathrm{I}_{\mathrm{G}}{ }^{1.3}$ as shown in Fig. 6. This identical signature observed for the diode $\left(-9 \mathrm{~V} \leq \mathrm{V}_{\mathrm{GS}}<-3 \mathrm{~V}\right)$ and for the transistor $\left(-9 \mathrm{~V} \leq \mathrm{V}_{\mathrm{GS}} \leq-2 \mathrm{~V}\right)$ can be imputed to the same noise sources, and thus to the same path for the electrons within gate to source (or drain) accesses (same signature, even for the GR centers above $1 \mathrm{kHz}$ ). The leakage current responsible for $\mathrm{I}_{\mathrm{G}}$ is of the same nature for the diode (under high reverse biases) and for the transistor (regardless the gate bias and at $\mathrm{V}_{\mathrm{DS}}=8 \mathrm{~V}$ ).

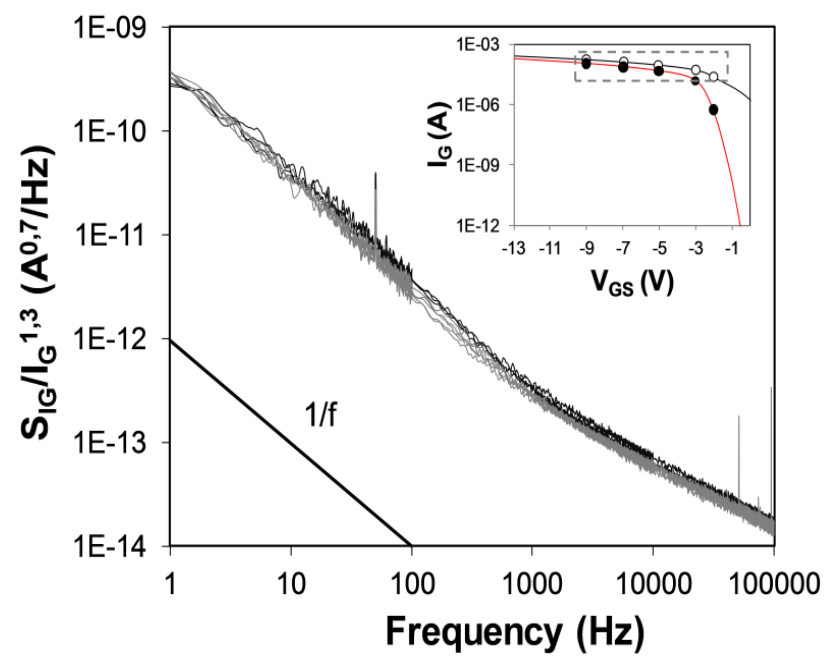

Fig. 6. Normalized gate noise current spectral density $\mathrm{S}_{\mathrm{IG}} / \mathrm{I}_{\mathrm{G}}^{1.3}$ for the Schottky diode $\left(-9 \mathrm{~V} \leq \mathrm{V}_{\mathrm{GS}}<-3 \mathrm{~V}\right.$, black plots $)$ under high reverse bias, and for the transistor $\left(\mathrm{V}_{\mathrm{DS}}=8 \mathrm{~V},-9 \mathrm{~V} \leq \mathrm{V}_{\mathrm{GS}} \leq-2 \mathrm{~V}\right.$, grey plots).

For these devices, $\mathrm{V}_{\mathrm{GS}}=-3 \mathrm{~V}$ stands as a knee value between two (or more) gate conduction mechanisms: the noise spectra $\mathrm{S}_{\mathrm{IG}}$ of the Schottky diode measured between $-3 \mathrm{~V} \leq \mathrm{V}_{\mathrm{GS}}<0 \mathrm{~V}$ do not fit the $\mathrm{I}_{\mathrm{G}}{ }^{1.3}$ power law anymore: other mechanisms are engaged leading to a change on the gate current origin. In this biasing zone, the generation-recombination (GR) centers and $1 / \mathrm{f}$ flicker noise of $\mathrm{S}_{\mathrm{IG}}$ spectra are featuring non monotonic behavior, revealing a change in the path of the biasing zone, the generation-recombination (GR) centers and 1/f flicker noise of $\mathrm{S}_{\mathrm{IG}}$ spectra are featuring non monotonic behavior, revealing a change in the path of the carriers or in the conduction mode through the gate (also confirmed by the fit of $\mathrm{I}_{\mathrm{G}}-\mathrm{V}_{\mathrm{GS}}$ versus analytical models). According to Zhang and al. [5], a leakage current model could be extracted explaining the contribution of each mechanism.

Fig. 7 is a schematic illustration of the HEMT under study representing where the gate leakage current flows. The location where OBIRCh measurements are carried out is indicated with red spots. $\mathrm{Wg}$ is the gate width wherein the laser beam irradiates. From our measurements, it can be assumed that:

(a) The current path (surface, vertical, or lateral leakage mechanisms) occurs in the same regions for the two configurations (between $\mathrm{G}-\mathrm{S}$ for the diode or between G-S \& G-D for the transistor).

(b) Moreover, whatever the gate current value (under the proposed $\mathrm{V}_{\mathrm{GS}}$ ranges), and both for the diode and for the transistor, the noise spectral density evolves with an $\mathrm{I}_{\mathrm{G}}{ }^{1.3}$ current law (the noise contributors are the same). These signatures can be partially correlated with the presence 
of very local current paths revealed by OBIRCh technique.

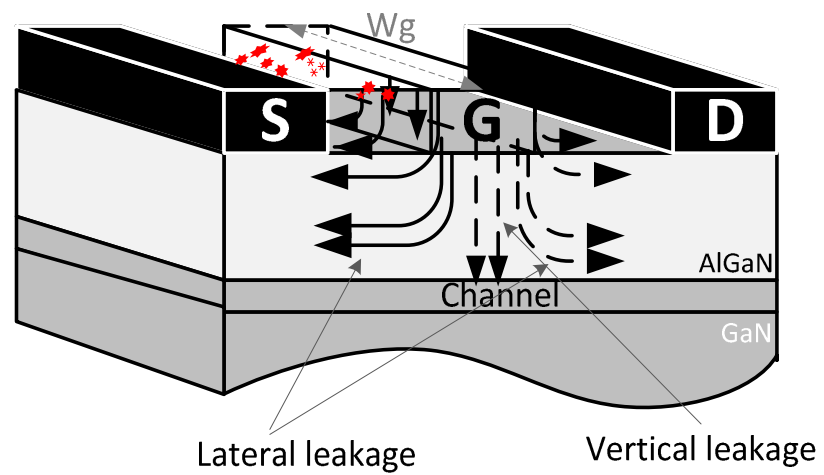

Fig. 7. Illustration of the HEMT AlGaN/GaN structure representing the vertical and lateral gate leakage current paths for the Schottky diode (solid lines) and for the transistor (gatesource diode solid lines and gate-drain diode dashed lines). The red spots illustrate the presence of very local current paths detected by OBIRCh technique.

\section{CONCLUSION}

This paper presents a synthesis issued from different experimental techniques (Electrical and Low Frequency Noise, OBIRCH) applied to the Schottky diode of an AlGaN/GaN HEMT. Gate conduction mechanisms and gate defects under reverse biasing are investigated in diode configuration and in transistor operating mode. From the investigations, it can be concluded that:

(a) Defects between gate and source are localized by OBIRCh and identified by LFN technique. $\mathrm{S}_{\mathrm{IG}}$ spectra feature $\mathrm{I}_{\mathrm{G}}{ }^{1.3}$ power law under high reverse biases, where a common origin of the gate leakage current is found for the diode and for the transistor. Moreover, spots measured by OBIRCh spread on a larger zone of the gate width as the gate to source voltage decreases (high reverse $\mathrm{V}_{\mathrm{GS}}$ ). This is consistent with the increase of the $\mathrm{I}_{\mathrm{G}}$ leakage current when $\mathrm{V}_{\mathrm{GS}}$ decreases.

(b) Trapping-detrapping centers are also detected with LFN measurements. These GR centers provide distinct trends at the vicinity of $\mathrm{V}_{\mathrm{GS}}=-3 \mathrm{~V}$. This is attributed to a change in the conduction mechanism of the leakage current, also tangible trough the analytical modeling of $\mathrm{I}_{\mathrm{G}}-\mathrm{V}_{\mathrm{GS}}$.

This study introduces a new methodology that can also be used to track gate related defects of $\mathrm{AlGaN} / \mathrm{GaN}$ HEMT before and after application of stresses. Improvement of technological processes can be reached by the identification and by the reduction of the defects involved in the failure mechanisms.

\section{ACKNOWLEDGEMENT}

The authors would like to thank ANR for the funding ReAGaN research program and all the partners of this project for fruitful discussions. They also want to acknowledge the University of Rouen for providing the necessary equipments for OBIRCh measurements.

\section{REFERENCES}

[1] H. Rao and G. Bosman "Device reliability study of high gate electric field effects in $\mathrm{AlGaN} / \mathrm{GaN}$ high electron mobility transistors using low frequency noise spectroscopy," $J$. of Applied Physics, vol. 108, September 2010.

[2] J.G. Tartarin, S. Karboyan, F. Olivie, G. Astre and B. Lambert, "I-DLTS, electrical lag and low frequency noise measurements of trapping effects in AlGaN/GaN HEMT for reliability studies," European Microwave Week Proceedings, 2011.

[3] K. Nikawa, S. Inoue, K. Morimoto and S. Sone "Failure analysis case studies using the IR-OBIRCH (infrared optical beam induced resistance change) method," Test Symposium,ATS'99 Proceedings. Eighth Asian, 1999.

[4] K. Sanchez, R. Desplats, F. Beaudoin, P. Perdu, S. Dudit, M. Vallet, and D. Lewis, "Dynamic thermal laser stimulation theory and applications," IEEE Reliability Physics Symposium Proceedings, 2006. 44 ${ }^{\text {th }}$ Annual, IEEE International.

[5] H. Zhang, E.J. Miller and E.T. Yu "Analysis of leakage current mechanisms in Schottky contacts to GaN and AlGaN/GaN grown by MBE," J. of Applied Physics, vol. 99, January 2006

[6] J.G. Tartarin, G. Soubercaze-Pun, J.L. Grondin, L. Bary, J. Mimila-Arroyo and J. Chavallier, "Generation-Recombination defects in $\mathrm{AlGaN} / \mathrm{GaN}$ HEMT on $\mathrm{SiC}$ substrate evidenced by low frequency noise measurements and SIMS characterization," International Conference on Noise Fluctuations, 2007. 